\title{
Stress Analysis of the Framework of a Device Designed for Scales Calibrating
}

\author{
Miroslav Blatnický ${ }^{1 *}$, Kateryna O. Kravchenko ${ }^{2}$ and Ján Dižo ${ }^{1}$ \\ ${ }^{1}$ University of Žilina, Department of Transport and Handling Machines, Univerzitná 8215/1, Žilina, \\ Slovak Republic; Email: miroslav.blatnicky@fstroj.uniza.sk,jan.dizo@fstroj.uniza.sk \\ ${ }^{2}$ Volodymyr Dahl East Ukrainian National University, Department of Rail Transport, Central \\ Avenue 59a, Sewerodonetsk, Ukraine; Email: kkatherina@ukr.net
}

\section{Corresponding Author: Miroslav Blatnický}

\begin{abstract}
This article is focused on the stress analyses of the welded structure of the device designed to the scales calibrating with maximum loading capacity up to ten tons. The article includes basic knowledges of the theory of elasticity and stress analysis and numerical method called Finite Element Method that were used for the task solution. Cores of the work were stress analyses of selected parts of the designed structure of the device. For stress analyses the ADINA numerical software was used. Results of analyses of the primary design device showed that strength in same locations did not respond to the required maximal load. The structure in critical locations was modified and subsequently reanalyses confirmed the sufficient strength with prescribed safety factor.
\end{abstract}

Keywords: Stress analysis, Finite element method, test device, vehicle axle scales.

\section{Introduction}

Measurement of weight belongs to one of the most often activities in technical laboratories. On one hand scales are used for the direct weight measurement and on other hand as an input in the measurement of derived physical quantities. In order to ensure measurement accuracy over the entire technical life of the scales, regular calibrations with precisely defined recalibration intervals are necessary.

The goal of this article is the presentation of stress analysis of selected parts of a newly designed testing device in order to enable carrying out experimental measurements to determine suitability of a scale for vehicle axles with maximum loading capacity up ten tons (Fig. 1). 


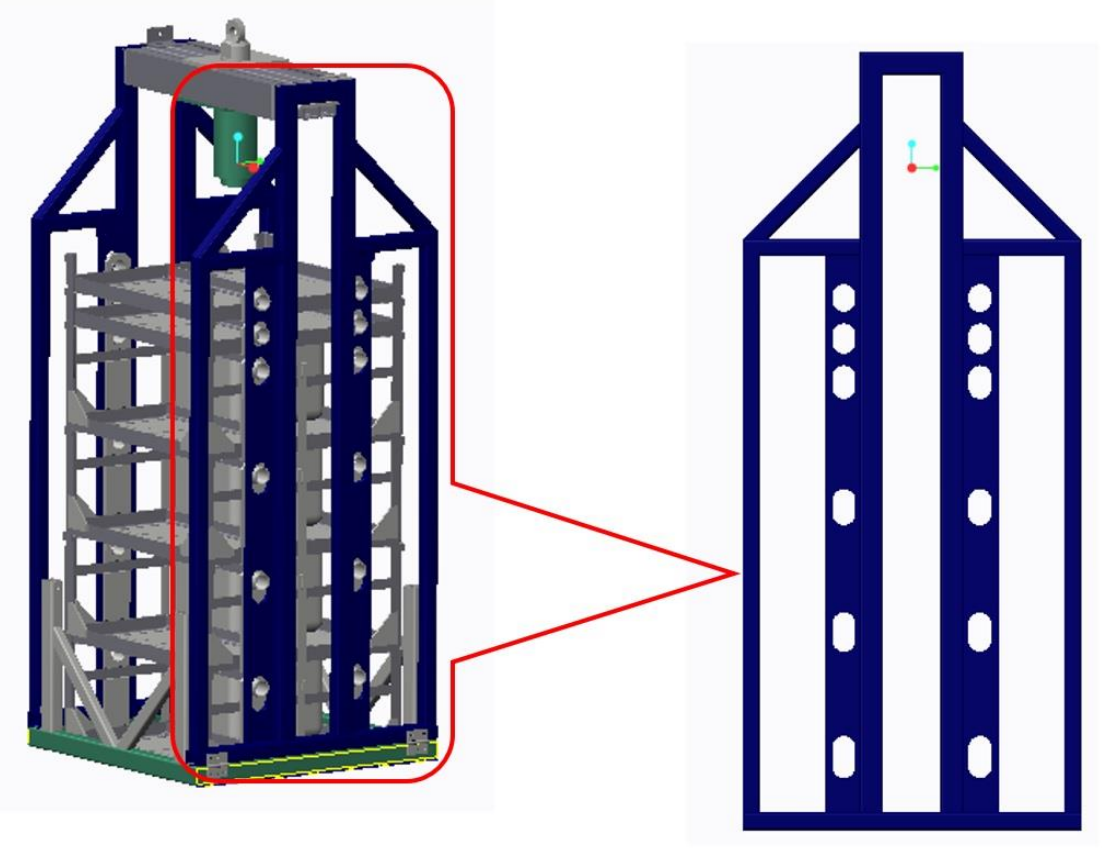

Fig. 1 CAD model of the designed device for scales calibrating (left) and view of the analysed framework (right). Source: [authors]

Since, currently, great emphasis is placed on efficiency, cost reduction and economically advantageous performance, this device will be subjected, prior to a prototype manufacture, to strength analysis with software support in order to determine whether the structure of designed device is able to withstand the given maximum load with a certain degree of safety. The importance of stress analysis lies in the investigation of the existing structure prototype, created in a virtual environment using a CAD system, in terms of its strength at the given load in the software environment, without a necessary preceding costly manufacture of the product. Based on the abovementioned stress analyses we can say in advance if analysed structure is satisfactory or, conversely, it needs further optimisation in order to prevent potential loss of life or property.

\section{Designed Device for Calibrating the Vehicle Axle Scales}

The whole device consists of several parts. The main part of the structure comprises two side plates, to which suspension means of thick metal sheet are welded. Here will be fitted suspension tubes of the boxes. On the top of this structure a hydraulic cylinder is placed. It is determined for lifting the whole structure and transmit the compressive force derived from the burdens onto a scale placed on a platform, through the girder, in order to calibrate the scale. The gravitational forces derived from the weights of individual boxes with weights and of the frame generate the main loading forces. The dominant stresses will include bending, pressure and shear, and we will examine their effect on the structure by stress analyses. 
Analyses will result in comparison of the observed values of stress, displacement and strain (deformation) of the designed structure with the permissible values that depend on the type of material, which will be used for it (strength, stiffness, etc.). Since we are dealing with a welded structure consisting of thin-walled sections, it will be modelled as a shell body using central line planes, with a subsequent thickness assignment. The designed steel structure will be gradually loaded with a burden weighting from 2 tons up to 10 tons, including its own weight and the structure will gradually lift the boxes containing weights, located inside the structure.

The structure is made of EN S355 (STN 11523) steel which the yield strength is $R_{Y}=320 \div 360 \mathrm{MPa}$ and the ultimate strength is $R_{U}=520 \div 640 \mathrm{MPa}$ [1]. The safety coefficient was chosen $c_{S}=2(-)$. For calculation we have chosen the lower limit of the interval. The permissible stress we can calculate as following:

$$
\sigma_{P}=\frac{R_{Y}}{c_{S}}=\frac{320}{2}=160.0 \mathrm{MPa}
$$

where $\sigma_{P}(M P a)$ represents the permissible stress, $R_{Y}(M P a)$ is the yield strength and $c_{S}(-)$ is safety coefficient. At the weld sites we must take into account the reduced permissible stress by the recommended $30 \%$, through introducing the welding effect coefficient $c_{W}=0.7(-)$. Hence, the permissible stress at the welded sites is calculated according to this equation:

$$
\sigma_{P W}=c_{W} \cdot \sigma_{P}=0.7 \cdot 160=112.0 M P a,
$$

where $\sigma_{P W}(M P a)$ is permissible stress in welds and $c_{W}(-)$ is the welding effect coefficient.

Complexity of the task requires the structure dividing into three main parts. They were both modelled and analysed separately. Into calculations we included mutual influences of individual parts. These results are equivalent to those that we would have got, if we had considered the complete structure. Parts of structure are box for weights, side plates and upper girder.

\section{Stress Analysis of the Side Plates of the Designed Device}

Nowadays there are many computer tools allowing investigation of strength and dynamic structural properties of individual bodies or complex mechanical systems composite of large number of bodies [2-5]. Finite Element Method is the most commonly used numerical technique based on the continuum mechanics [6-7] allowing mainly the investigation and determination of the stresses and strains in materials [8-11] and structures subjected to forces, torques etc. [12-13]. 

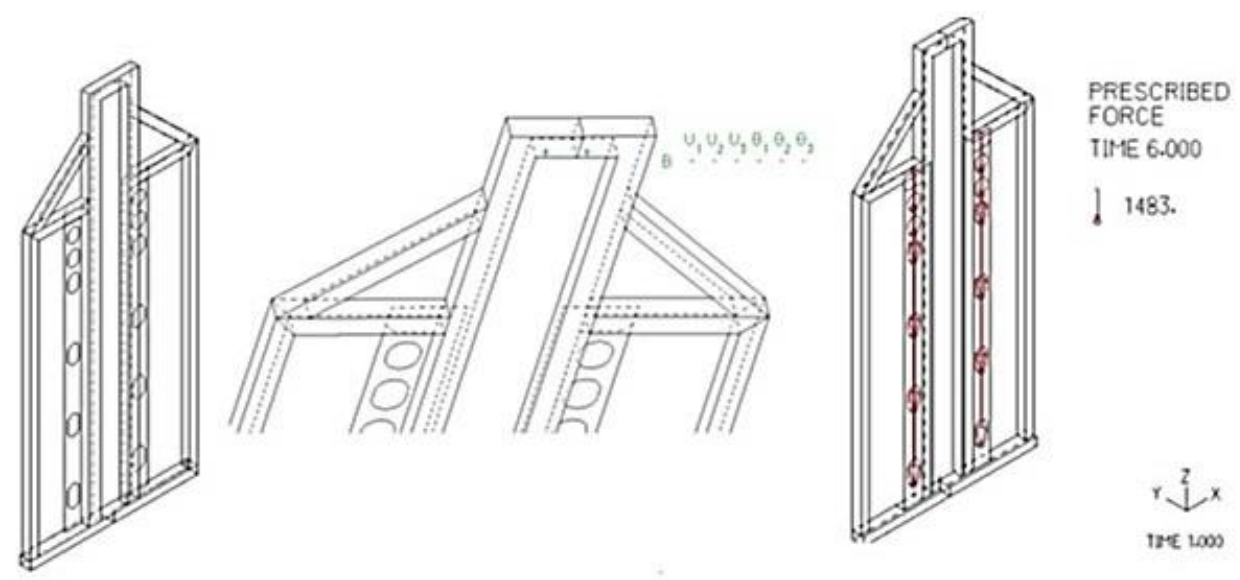

Fig. 2 Shell model of the side plate, boundary conditions and load. Source: [authors]

The side plate geometry was created as a shell structure in PreProcessor modulus of ADINA software (Fig. 2 left) in compliance with the design modelled in Inventor software. Then we can define boundary conditions (Fig. 2 middle) and load (Fig. 2 right).

Table 1 Time functions $1-6$ defining the gradual load of boxes. Source: [authors]

\begin{tabular}{ccccccc}
\hline $\begin{array}{l}\text { Time } \\
\text { [s] }\end{array}$ & $\begin{array}{c}\text { Function } \\
\text { value 1 }\end{array}$ & $\begin{array}{c}\text { Function } \\
\text { value 2 }\end{array}$ & $\begin{array}{c}\text { Function } \\
\text { value 3 }\end{array}$ & $\begin{array}{c}\text { Function } \\
\text { value 4 }\end{array}$ & $\begin{array}{c}\text { Function } \\
\text { value 5 }\end{array}$ & $\begin{array}{c}\text { Function } \\
\text { value 6 }\end{array}$ \\
\hline $\mathbf{0}$ & 0 & 0 & 0 & 0 & 0 & 0 \\
\hline $\mathbf{1}$ & 1 & 0 & 0 & 0 & 0 & 0 \\
\hline $\mathbf{2}$ & 1 & 1 & 0 & 0 & 0 & 0 \\
\hline $\mathbf{3}$ & 1 & 1 & 1 & 0 & 0 & 0 \\
\hline $\mathbf{4}$ & 1 & 1 & 1 & 1 & 0 & 0 \\
\hline $\mathbf{5}$ & 1 & 1 & 1 & 1 & 1 & 0 \\
\hline $\mathbf{6}$ & 1 & 1 & 1 & 1 & 1 & 1 \\
\hline
\end{tabular}

Table 2 Forces values applied at individual time functions. Source: [authors]

\begin{tabular}{ccc}
\hline Force & Value [N] & Time function [s] \\
\hline $\mathbf{F}_{\mathbf{1}}$ & $1,483.0$ & 1 \\
\hline $\mathbf{F}_{\mathbf{2}}$ & $1,483.0$ & 2 \\
\hline $\mathbf{F}_{\mathbf{3}}$ & $5,140.0$ & 3 \\
\hline $\mathbf{F}_{\mathbf{4}}$ & $5,140.0$ & 4 \\
\hline $\mathbf{F}_{\mathbf{5}}$ & $5,140.0$ & 5 \\
\hline $\mathbf{F}_{\mathbf{6}}$ & $5,140.0$ & 6 \\
\hline
\end{tabular}


By reason that the request of the stepwise loading is demanded on the structure regarding the exact calibration of scale, the load was applied by several time functions (Tab. 1). Each of time functions will be used at defining the load. The load is applied in the form of single forces entered in points (Fig. 2 right). These forces are caused by the weight of individual boxes that will begin to act on the structure by gradual ejection of the hydraulic cylinder connecting the weight and the structure. Values of these forces are introduced in Tab. 2.

It follows from Tab. 1 and Tab. 2, that the side plate is subjected at time $6 s$ to the force, that is twice the sum $F_{1} \div F_{6}$ (side plate has two parallel suspensions) of the value $F_{\text {sum }}=47,052.0 \mathrm{~N}$. The values of individual forces are determined as the sum of the forces from the weight mass and the box mass, where the box mass (weight) was calculated in ADINA software. Furthermore, we prescribe to the structure also a load resulting from its own weight, which is $m=204.05 \mathrm{~kg}$. Thus, the gravitational force will be $F_{G}=2,001.7 \mathrm{~N}$. The side plate is fixed-end mounting on surface (Fig. 2 middle) and loaded by total loading force $F_{T L}$ which is given as the sum of $F_{\text {sum }}$ and $F_{G}$. It means that the total loading force is $F_{T L}=49,053.7 \mathrm{~N}$.

When the general settings, material properties and boundary conditions are entered, the "element group" assigning individual bodies of the structure is following. The element type was prescribed the same for all bodies - shell element type. For this part of the structure was only one element group used of the thickness corresponding to the thickness of seamless square tube used for the side plate. For the calculation accuracy there are important correct option for the mesh density, mesh algorithm and type of elements. We chose mesh density of $5 \mathrm{~mm}$ and the Advancing Front with linear tetrahedrons mesh algorithm. After model meshing we launched calculation. After its successful running we checked analysis results in PostProcessor modulus of ADINA software (Fig. $3)$.

Numerical analysis shows (Fig. 3 left), that the larges reduced stress according to the $\mathrm{HMH}$ hypothesis is in the location 1 and it reaches the value of $184.5 \mathrm{MPa}$. But this values exceeds the permissible stress of $112.0 \mathrm{MPa}$. Further after showing displacement (Fig. 3 right) we can see that the lower part of this structure is displaced by the force effect along the axis y (out of the structure) of the value of $7.132 \mathrm{~mm}$. When we look closer in Fig. 1, then we can find out the side plate is jointed to the lower frame by two hinges, which will restrain displacement along axis $y$. We have to determine values of the shear force in these locations in order to accurate dimension. We will find out this so that we will restrain degree of freedom along the axis $y$ in the locations of hinges. 


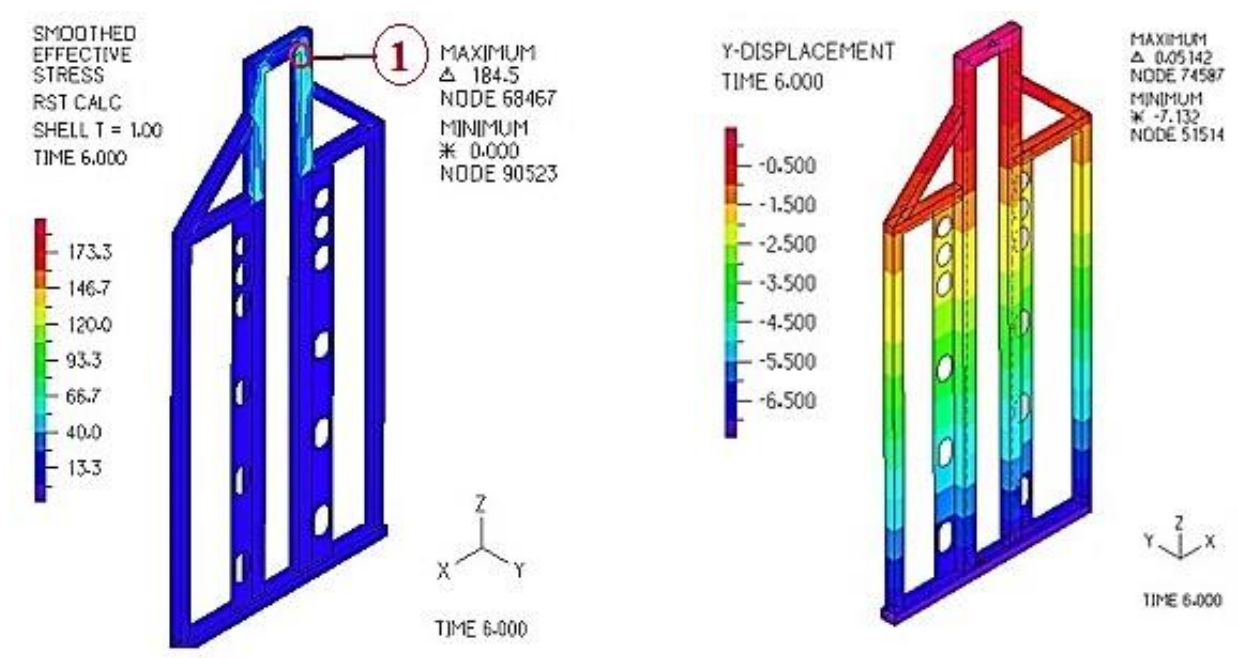

Fig. 3 Reduced HMH stress in side plates structure (left) and displacement along axis y (right).

Source: [authors]

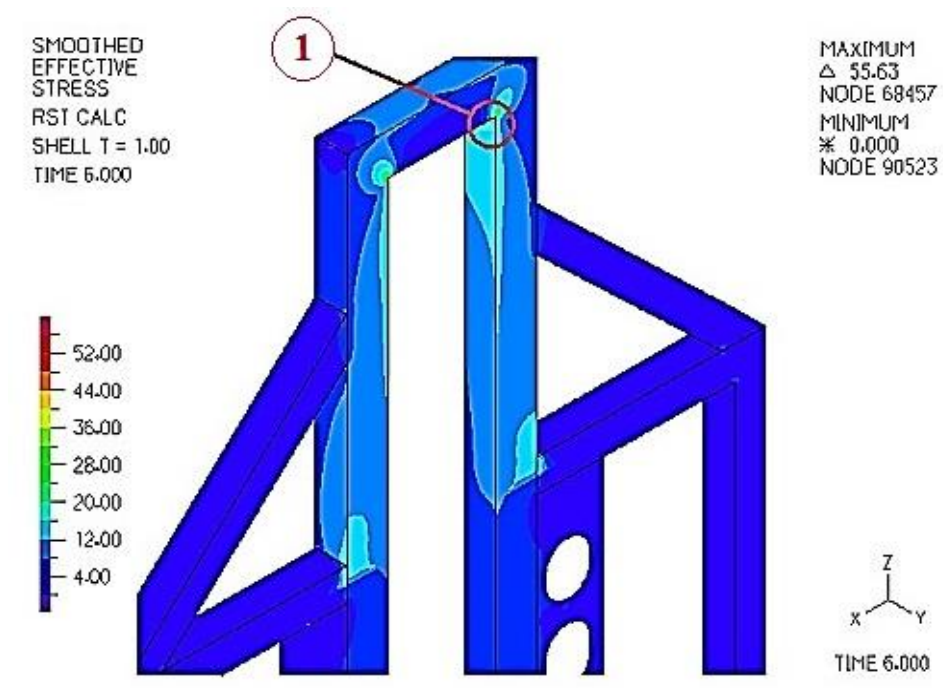

Fig. 4 Reduced HMH stress in the analysed side plates following the structural modification.

Source: [authors]

Based on these facts, we made the needed structural modification for stress reduction in the location 1. It was proposed to modify the thickness from the original $5 \mathrm{~mm}$ to $10 \mathrm{~mm}$. This designed structural modification caused a reduction of the stress in the location 1 on the value of $55.63 \mathrm{MPa}$ (Fig. 4) and it means this structural modification guarantees the safety factor satisfying.

\section{Conclusion}

The article deals with the stress analysis of selected parts of the designed device, which will serve to calibrating the vehicle axle scales up to ten tons. In the course of issue solving, we decided to divide the structure into three main parts, namely box for weights, side plates, and upper girder. Using the structure's draft modelled in the CAD software Inventor we modelled individual parts of the 
considered structure in ADINA software. The stress analyses were carried out in ADINA software. We found out that original designed structure was not suitable in same location for required load transmitting. Therefore there was necessary to perform additional structure modifications in most exposed locations. After reanalyses we compared calculated results with ultimate stresses. Calculations detected the proposed structure modification fully complied the safety requirements load factor more than three.

\section{Acknowledgments}

The work was supported by the Cultural and Educational Grant Agency of the Ministry of Education of the Slovak Republic in project No. KEGA 077ŽU-4/2017: Modernization of the Vehicles and engines study program.

\section{References}

[1] Bajla, J., Broncek, J., Antala, J \& Sekereova, D. (2014). Mechanical Engineering Tables (In Slovak). Selection standard. Slovak Office Standards, Metrology and Testing. ISBN 978-808130-039-4.

[2] Harusinec, J., Suchanek, A, Gerlici, J. \& Lack, T. (2012). Locomotive brake unit modification for laboratory experimental tests. In Dynamics of rigid and deformable bodies 2012 (electronic source): Proceedings of international scientific conference, Usti nad Labem, Czech Republic, 10 - 12 October 2012 (9 pages). Ústí nad Labem, Czech Republic.

[3] Svoboda, M. Soukup, J. (2013). Verification of numeric solution by experiment for examination vertical oscillation of a mechanical system. Manufacturing Technology, 13(4), 559-563.

[4] Hauser, V., Stastniak, P., Gerlici, J. \& Lack, T. (2014). Design solution of stanchions mechanism for goods mounting during transport on the Shimmns wagon. In: Innovations in conception, design, production and testing the freight wagons I.: Proceedings of conference, Žilina, Slovak Republic, 27 - 28 November 2014 (pp. 47-53). Žilina, Slovak Republic.

[5] Suchanek, A., J. Harusinec, J., Gerlici, J. \& Lack, T. (2013). Analysis of models for simulation computations and experimental detection of stress in braked railway wheel In: TRANSCOM 2013: 10th European conference of young researchers and scientists: Žilina, June 24-26, 2013, (pp. 283 - 287). Slovak Republic. Žilina, University of Žilina.

[6] Klimenda, F., Skocilasova, B. (2015). Rollers vibration of pipe conveyor. Manufacturing Technology, 15(6), 991-995.

[7] Bathe, K. J. (1996). Finite Element Method. Prenice-Hall, Inc. New Jersey. 
[8] Lack, T., Gerlici, J. \& Manurova, M. (2016). Freight car bogie properties analysis by means of simulation computations. Manufacturing Technology, 16(4), 667-672.

[9] Štastniak, P., Gerlici, J., Lack, T. \& Harusinec, J. (2013). Computer aided simulation analysis for computation of modal analysis of the freight wagon. In: TRANSCOM 2013: 10th European conference of young researchers and scientists: Žilina, June 24-26, 2013, (pp. 297300). Slovak Republic. Žilina, University of Žilina.

[10] Gerlici, J., Lack, T. (2014). Rail vehicles brake components test bench utilisation. Applied Mechanics and Materials, 486, 379-386.

[11] Gerlici, J., Lack, T. \& Harusinec, J. (2014). Development of test stand prototype for rail vehicles brake components testing. Komunikacie, 16(3A), 27-32.

[12] Melnik, R., Sowinski, B. (2014). The analysis of rail vehicle model eigenvalues for suspension fault detection method. In: $14^{\text {th }}$ Mini Conference on Vehicle system Dynamics, Identification and Anomalies, VSDIA 2014, Budapest University of Technology and Economics, Hungary, 10 - 12 November, 2014, (pp. 39-46). Hungary, Budapest.

[13] Steisunas, S., Bureika, G. (2014). Study of freight wagon running dynamic stability taking into account the track stiffness variation. Transport Problems, 9(4), 131-143. 